\title{
miRNA-128 modulates bone neoplasms cells proliferation and migration through the WNT/ $\beta$-catenin and EMT signal pathways
}

Yang Li, Xiaotao Long, Ji Wang, Jing Peng and Kai Shen*

\begin{abstract}
Background: Bone neoplasms present poor prognosis due to recurrence and metastasis. Although the role microRNAs (miRNAs) in inhibiting growth and metastasis of bone neoplasms has been investigated, the underlying potential molecular mechanisms mediated by miRNA-128 (miR-218) for the invasiveness of bone neoplasms cells are still not completely understood. The purpose of this study was to identify the regulatory mechanisms of miR218 in bone neoplasms cells.

Methods: Western blotting, quantitative reverse transcription-polymerase chain reaction (qRT-PCR), Counting Kit-8 assay, terminal deoxynucleotidyl transferase-mediated dUTP nick end labeling (TUNEL) staining, luciferase activity assay immunofluorescence, and immunohistochemistry were used to analyze the regulatory effects of miR-218 on bone neoplasms cells.

Results: Here, the results showed that transfection of miR-128 suppressed bone neoplasms cells proliferation, migration, and invasion. Genetic knockdown of miR-128 in bone neoplasms cells suppressed the activation of the Wnt/ $\beta$-catenin and epithelial-mesenchymal transition (EMT) signaling pathways. Activation of Wnt or EMT blocked miR-128-inhibited cells proliferation and migration in bone neoplasms cells. Exogenously introduced miR-128 markedly inhibited tumor regeneration in bone neoplasms xenograft models.

Conclusions: These results define a tumor-regulated function for miR-128 in bone neoplasms by down-regulation of the Wnt/ $\beta$-catenin and EMT signal pathways, which provided a potential target for bone neoplasms gene therapy.
\end{abstract}

Keywords: miRNA-128, Bone neoplasms, Proliferation, Migration, Wnt/ß-catenin, EMT

\footnotetext{
*Correspondence: kai_shenedu@163.com

Department of Orthopedics, Chongqing General Hospital, University of the Chinese Academy of Sciences, No. 312 Zhongshanyi Road, Yuzhong District, Chongqing 400013, China
}

(c) The Author(s). 2021 Open Access This article is licensed under a Creative Commons Attribution 4.0 International License, which permits use, sharing, adaptation, distribution and reproduction in any medium or format, as long as you give appropriate credit to the original author(s) and the source, provide a link to the Creative Commons licence, and indicate if changes were made. The images or other third party material in this article are included in the article's Creative Commons licence, unless indicated otherwise in a credit line to the material. If material is not included in the article's Creative Commons licence and your intended use is not permitted by statutory regulation or exceeds the permitted use, you will need to obtain permission directly from the copyright holder. To view a copy of this licence, visit http://creativecommons.org/licenses/by/4.0/. The Creative Commons Public Domain Dedication waiver (http://creativecommons.org/publicdomain/zero/1.0/) applies to the data made available in this article, unless otherwise stated in a credit line to the data. 


\section{Introduction}

Bone neoplasms originate from bone and rapidly spread to the rest of tissues in the patients [1]. The main reason for the poor prognosis of bone neoplasms is recurrence and metastasis, and the 5-year survival rate of bone neoplasms is less than $30 \%$ [2]. At present, the issue of controlling the early metastasis of bone neoplasms has become a bottleneck in the treatment of this disease [3, 4]. Although many therapeutic protocols such as surgical therapy, chemoradiotherapy, and immunotherapy have been applied in bone neoplasms patients, the prognosis of clinical patients remains poor for short of effective therapeutic targets [5-9].

MicroRNAs (miRNAs) are endogenous, small noncoding RNAs with 18-25 nucleotides, which can transcribe from nonprotein coding genes or introns, and play multifunctional roles by regulating gene expression at a posttranscriptional level through binding to the 3 '-untranslated regions of target genes [10-12]. Many reports have shown that proliferation and metastasis of human tumor cells are accompanied by abnormal expression of miRNAs [13-15]. Recently, miRNAs have been reported to be involved in tumor cells growth, proliferation, migration, differentiation, apoptosis aging, and death [16-19]. Ectopic expression of multiple miRNAs has been found during bone metastasis by targeting important osteoclast genes [20]. Results indicate that miRNA-128 (miR-128) is more highly expressed in drug-resistant breast cancer samples compared to drugsensitive samples, and the decrease of miRNA-128 enhances the sensibility of breast cancer cells to chemodrugs by targeting $\mathrm{B}$ cell lymphoma 2-associated X (Bax) [21]. Findings also have showed that miR-128 is reduced in prostate cancer, and exogenously introduced miR-128 suppresses tumor regeneration in multiple prostate cancer xenograft models by targeting the stem cell regulatory factors B cell-specific Moloney murine leukemia virus insertion site 1 (BMI-1), NANOG, and transforming growth factor beta receptor 1 (TGFBR1) [22]. However, the mechanism by which miR-128 influences bone tumor cells osteoclast differentiation remains unclear.

Inactivation of the Wnt/ $\beta$-catenin and epithelialmesenchymal transition (EMT) signal pathways is involved in human osteosarcoma growth by arresting cell cycle in $G 2 / M$ phase [23]. In addition, EMT signaling pathway plays an important role in osteosarcoma growth proliferation, and invasion [24-26]. In this study, we investigated the role of miR-128 in bone neoplasms cells proliferation and migration, and further explored the associations between miR-128 and tumor invasion-related signal pathways in bone tumor cells.

\section{Materials and methods}

\section{Tissue samples}

Bone cancer tissues and matched adjacent normal tissues were collected from 18 patients (9/9: male/female, age $57.5 \pm 6.5$ years old) after surgical resection. The expression of miR-128 of tissues was evaluated using quantitative reverse transcription-polymerase chain reaction (qRT-PCR).

\section{Cell line and cell culture}

Bone cancer cell line Mg63 cells were purchased from BeNa Culture Collection (Shanghai, China) and cells were cultured in (Dulbecco's modified Eagle medium (DMEM, Thermo Fisher Scientific, Inc.) supplemented with $10 \%$ fetal bovine serum (FBS, Thermo Fisher Scientific, Inc.). Normal bone cell line hFOB1.19 was a gift from Tumor Pathology Laboratory, Chongqing Medical University, and cultured in DMEM supplemented with $10 \%$ FBS, $1 \%$ penicillin, and $1 \%$ streptomycin. All cells were cultured at $37{ }^{\circ} \mathrm{C}$ in a humidified incubator with $5 \% \mathrm{CO}_{2}$.

\section{qRT-PCR}

Expression of miR-128 was evaluated using qRT-PCR. Briefly, total RNA was extracted from tissues or cells using RNeasy kits (QIAGEN, Valencia, CA, USA). RNA was reversely transcribed into cDNA using miRNAspecific RT primers (Thermo Fisher Scientific Inc., Waltham, MA, USA). The used primer sequences (Invitrogen, Shanghai, China) were as follows: miR-128, 5' -TCCGATCACAGTGAACCGGT-3' (forward) and 5'-GTGCAGGGTCCGAGGT-3' (reverse); U6, 5' CTCGCTTCGGCAGCACA-3' (forward) and 5'-AACG CTTCACGAATTTGCGT-3' (reverse). qRT-PCR was performed by a TaqMan miRNA qRT-PCR assays (Applied Biosystem, Waltham, MA, USA) with ABI-Prism 7300 System (Applied Biosystem, Waltham, MA, USA). Expression of miR-1258 was measured using $2^{-\Delta \Delta C t}$ as described previously [27].

\section{Knockdown of miR-128}

Si-RNAs sequences for miR-128 (si-miR-128; 5'-UCACAGUGAACCGGUCUCUUU-3') and miR-mimic negative control (si-NC; 5'-UGGUUUACAUGUUU UCCUA-3') were obtained from Invitrogen Co., Ltd. (Shanghai, China). Cells were transfected with si-miR$128(50 \mathrm{nM})$ of or si-NC (50 nM) using Lipofectamine 3000 (Thermo Fisher Scientific, Inc., Waltham, MA, USA) according to the manufacturer's instructions. After $96 \mathrm{~h}$ of transfection, cells were used for further analyses.

\section{Gene overexpression}

DNA sequences of Wnt and E-cadherin were amplified using human bone cells cDNA library, and cloned into a plasmid expression vector pcDNA3.1 (Invitrogen, Carlsbad, CA, USA) to generate Wnt overexpressing (pWnt) or E-cadherin overexpressing plasmids (pE-cad). The miR-128 knockdown Mg63 cells were transfected with 
pWnt, pE-cad, or a control empty plasmid (Control) using a Lipofectamine 3000 (Thermo Fisher Scientific, Inc., Waltham, MA, USA). Cells were used for further analyses after $72 \mathrm{~h}$ of transfection.

\section{Cell proliferation assay}

Cell proliferation was analyzed using Counting Kit-8 (CCK-8, Dojindo Molecular Technologies, Inc., Kumamoto, Japan) assays following the manufacturer's instructions. In brief, Mg63 cells $\left(1 \times 10^{3}\right)$ were seeded in 96-well plates and cultured at $37{ }^{\circ} \mathrm{C}$ for $72 \mathrm{~h}$. After cultures, CCK- 8 solution was added for $1 \mathrm{~h}$ at $37^{\circ} \mathrm{C}$. The optical density (OD) was recorded at $450 \mathrm{~nm}$ using a microplate reader (Multiscan FC; Thermo Fisher Scientific, Inc., Waltham, MA, USA). Cell proliferation was analyzed using Image-Pro 5.0 software (Media Cybernetics, Bethesda, MD, USA).

\section{TUNEL staining}

Mg63 cells $\left(1 \times 10^{4}\right)$ were fixed with paraformaldehyde (4\%) at $25{ }^{\circ} \mathrm{C}$ for $30 \mathrm{~min}$, and permeabilized with $0.1 \%$ Triton-X-100 at $25{ }^{\circ} \mathrm{C}$ for $5 \mathrm{~min}$. Apoptosis of Mg63 cells was analyzed using terminal deoxynucleotidyl transferase-mediated dUTP nick end labeling (TUNEL) assay (Sigma, Germany) according to the manufacturer's protocols. Briefly, cells were incubated with TUNEL for $1 \mathrm{~h}$ at $4{ }^{\circ} \mathrm{C}$, washed with phosphate buffer saline (PBS), and then incubated with 5\% 4',6'-diamidino-2-phenylindole (DAPI, Sigma-Aldrich, St. Louis, MO, USA) for 15 min at $25^{\circ} \mathrm{C}$. Finally, images were captured using Olympus IX73 microscope (Tokyo, Japan), and the apoptosis rate of cells was calculated by the software of Developer XD 1.2 (Definiens AG, Munich, Germany).

\section{Cell cycle analysis}

Mg63 cells $\left(1 \times 10^{7}\right)$ were collected, washed with PBS, and fixed in ethanol (70\%) for $2 \mathrm{~h}$ at $4{ }^{\circ} \mathrm{C}$. Cells were then incubated with RNase A $(10 \mathrm{mg} / \mathrm{L})$ for $30 \mathrm{~min}$ at $37{ }^{\circ} \mathrm{C}$, washed with $\mathrm{PBS}$ and subsequently incubated in PI $(10 \mathrm{~g} / \mathrm{mL})$ for $1 \mathrm{~h}$ at $4{ }^{\circ} \mathrm{C}$. Cell cycle distribution was analyzed using Flow cytometry. The results were quantified using ModFit software version 3.0 (BD Biosciences, San Jose, CA, USA).

\section{Cell migration and invasion assay}

Mg63 cells $\left(1 \times 10^{5}\right)$ were cultured in Matrigel-uncoated and -coated transwell inserts ( $8 \mu \mathrm{m}$ pore size; Millipore). For migration assay, Mg63 cells at density of $1 \times 10^{5} / \mathrm{mL}$ were placed into the upper chamber with the noncoated membrane. For invasion assay, Mg63 cells were suspended as a density of $1 \times 10^{5} / \mathrm{mL}$ in $500 \mu \mathrm{L}$ DMEM containing $10 \% \mathrm{FBS}$. The cells were then subjected to the tops of $\mathrm{BD}$ BioCoat Matrigel Invasion Chambers (BD Biosciences, San Jose, CA, USA) according to the manufacturer's protocol. After $48 \mathrm{~h}$ of incubation, $\mathrm{Mg} 63$ cells were fixed in $4 \%$ paraformaldehyde at $25{ }^{\circ} \mathrm{C}$ for 15 min, and stained with $0.1 \%$ crystal violet dye (Sigma-Aldrich) at $25{ }^{\circ} \mathrm{C}$ for $15 \mathrm{~min}$. The cells were counted at three randomly selected views using a light microscope (Olympus, Tokyo, Japan).

\section{Western blotting}

The total cellular proteins were extracted from cultured Mg63 cells $\left(1 \times 10^{7}\right)$ using radioimmunoprecipitation assay (RIPA) lysis buffer (Sigma-Aldrich, St. Louis, MO, USA). Cells were centrifuged at $12,000 \times g$ at $4{ }^{\circ} \mathrm{C}$ for 15 min, and supernatant was collected. Protein concentration was determined by the BCA Protein Assay kit (Thermo Fisher Scientific, Inc., Waltham, MA, USA). A total of $30 \mu \mathrm{g}$ of protein was separated on $12.5 \%$ sulfatepolyacrylamide gel electrophoresis (SDS-PAGE), and bolted onto a polyvinylidene fluoride (PVDF) membrane (Thermo Fisher Scientific, Inc., Waltham, MA, USA). Protein was blocked using $5 \%$ bovine serum albumin (BSA, Sigma-Aldrich, St. Louis, MO, USA) at $25^{\circ} \mathrm{C}$ for 2 $\mathrm{h}$, and then incubated with primary antibodies including Wnt (ab228526), $\beta$-catenin (ab32572), E-cadherin (ab76319), vimentin (ab92547), fibronectin (ab45688), caspase-3 (ab13847), caspase-9 (ab2020068), bone morphogenetic protein-2 (BMP-2, ab14933), vascular endothelial growth factor (VEGF, ab53465), Cyclin D1 (ab16663), Cyclin E2 (, ab32103), and $\beta$-actin (ab8226) at $4{ }^{\circ} \mathrm{C}$ for $12 \mathrm{~h}$. All primary antibodies were purchased from Abcam, Cambridge, MA, USA, and used at a dilution of 1:1000. Membranes were then incubated with HRP-conjugated goat anti-rabbit IgG mAb secondary antibodies (1:5,000, cat. no. 4410, Cell Signaling Technology. Inc., Danvers, MA, USA) at $25^{\circ} \mathrm{C}$ for $2 \mathrm{~h}$. The immunoreactivity was evaluated using ECL Western blotting kit (Beyotime Institute of Biotechnology, Beijing, China). The density of protein was analyzed using ImageJ software 2.0 (Bio-Rad, USA) and normalized to $\beta$-actin.

\section{Luciferase activity assay}

To validate direct targeting of miR-128, Wnt 3'UTR containing predicted miR-128 binding sites was amplified, subcloned into pGL3-control vectors (Promega, Fitchburg, WI, USA), and co-transfected with mimic miRNAs in Mg63 cells. Wild-type (WT) Wnt reporter and mutant type (MUT) Wnt reporter with mutant miR-128 binding sites were constructed using QuikChange II Site-Directed Mutagenesis Kit (Agilent Technologies, Santa Clara, CA, USA) according to the manufacturer's instructions. After 72-h transfection, relative luciferase activity was analyzed using dualluciferase reporter assay (Promega, Fitchburg, WI, USA) according to the manufacturer's instructions. 

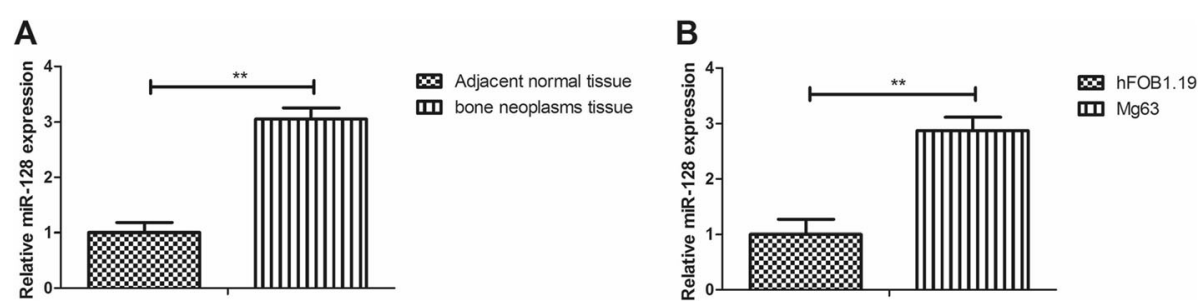

Fig. 1 Expression of miR-128 in bone cancer tissues and Mg63 cells. a miR-128 expression in bone cancer tissues and adjacent normal tissues was measured. $\mathbf{b}$ miR-128 expression was measured by qRT-PCR in bone Mg63 cells and normal bone hFOB1.19 cells. ${ }^{* *} P<0.01$

\section{Tumor xenograft assay}

A total of 16 female nude mice at age of 6 weeks weighting 28-32 g were purchased from Animal Experimental Center of Chongqing Medical University (Shanghai, China). Mice were housed $23 \pm 0.5{ }^{\circ} \mathrm{C}$, humidity of $50 \pm 5 \%$, a 12-h light/ dark cycle, and free accessed to food and water in specific pathogen-free condition. Mg63 cells $\left(1 \times 10^{5}\right)$ transfected with Si-miR-128 or Si-NC were subcutaneously injected into the right flank of mice ( $n=8$ per group). Mice were sacrificed using cervical decapitation on week 10 , and tumors were isolated from xenograft, weighted, and used for immunohistochemistry (IHC) analysis.

\section{IHC analysis}

Tissue samples were embedded in paraffin, cut into $4 \mu \mathrm{m}$ thickness sections, deparaffinized in xylene, rehydrated

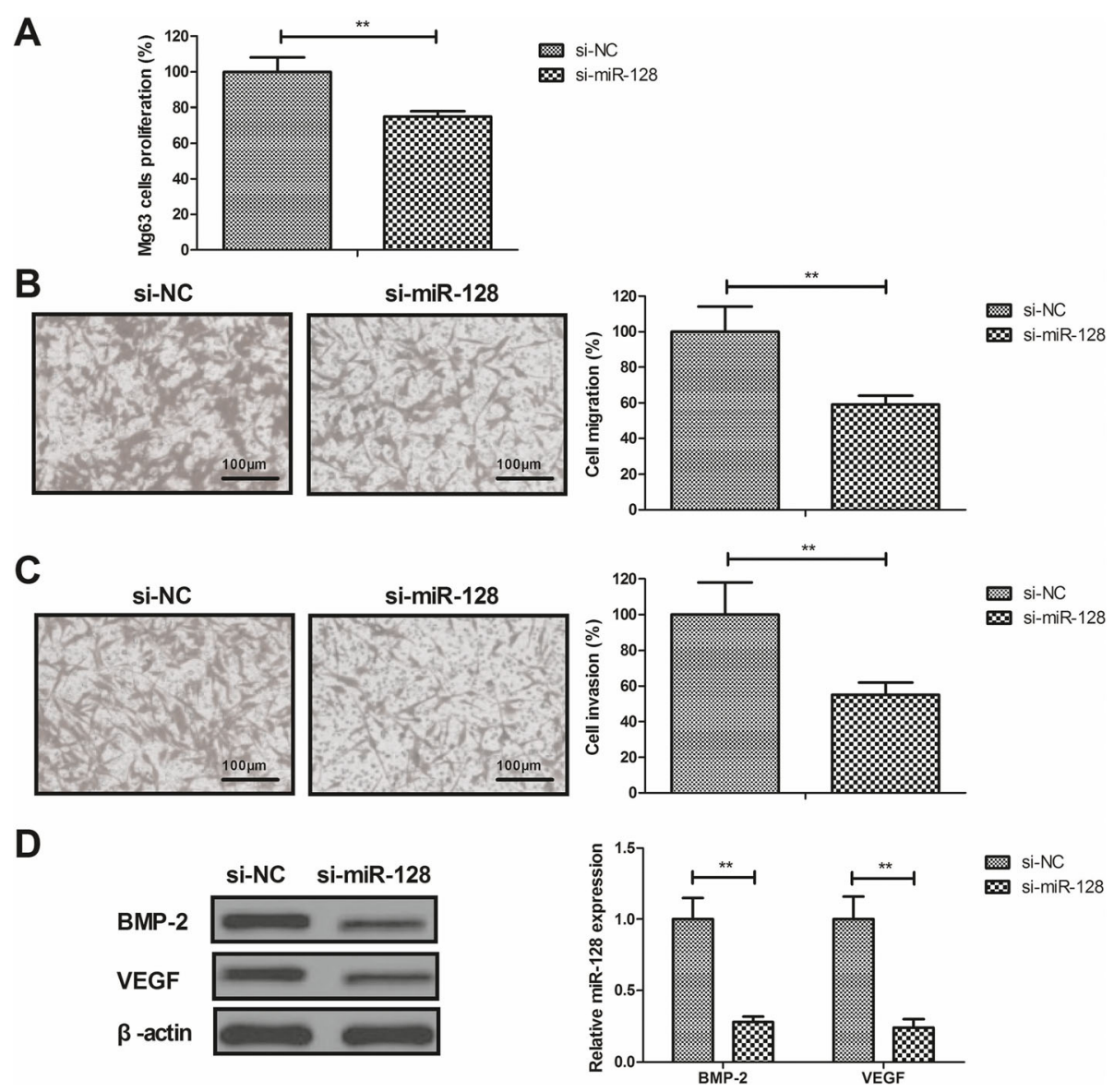

Fig. 2 Knockdown of miR-128 inhibited Mg63 cells proliferation, migration, and invasion. Inhibitory effects of si-miR-128 transfection on proliferation (a), migration (b), and invasion (c) of Mg63 cells. d Protein expression of BMP-2 and VEGF in si-miR-128-transfected Mg63 cells. **P < 0.01 vs. Si-NC 
through graded ethanols, and blocked in 3\% hydrogen peroxide for $10 \mathrm{~min}$ at $25^{\circ} \mathrm{C}$ as previously described [28]. Tumor sections were incubated with specific primary antibodies Wnt (1:1,000 dilution, ab228526), $\beta$-catenin (1:1, 000 dilution, ab32572), E-cadherin (1:1,000 dilution, ab76319), vimentin (1:1,000 dilution, ab92547), fibronectin (1:1,000 dilution, ab45688) for $12 \mathrm{~h}$ at $4{ }^{\circ} \mathrm{C}$. Tumor tissues were then incubated with secondary antibody (Alexa Fluor 488, 1:2,000 dilution) at $25^{\circ} \mathrm{C}$ for $2 \mathrm{~h}$. All antibodies were purchased from Abcam, Cambridge, MA, USA. The results were captured at $\times 40$ magnifications using the Olympus IX73 microscope (Tokyo, Japan).

\section{Statistical analysis}

All data were presented as the mean \pm standard deviation (SD). Statistical analyses were conducted using one-way analysis of variance (ANOVA) followed by Bonferroni's adjustment where there were multiple comparisons in Statistical Product and Service Solutions software (SPSS 17.0 for Windows, SPSS, Chicago, IL, USA). Significance was accepted at $P<0.05$.

\section{Results}

miR-128 expression was increased in bone neoplasms tissues and Mg63 cells

To investigate the effect of miR-128 on bone tumor, its expression was accessed in bone neoplasms tissues and cell line Mg63 cells by qRT-PCR. The results revealed that miR-128 expression was higher in bone neoplasms tissues than adjacent normal tissues $(P<0.01$; Fig. 1a). It was also demonstrated that miR-128 was highly expressed in bone neoplasm Mg63 cells compared to normal bone hFOB1.19 cells $(P<01$; Fig. $1 b)$.

Knockdown of miR-128 inhibited proliferation, migration and invasion of Mg63 cells

The anti-cancer effects of miR-128 were investigated in Mg63 cells in vitro. The results demonstrated that,
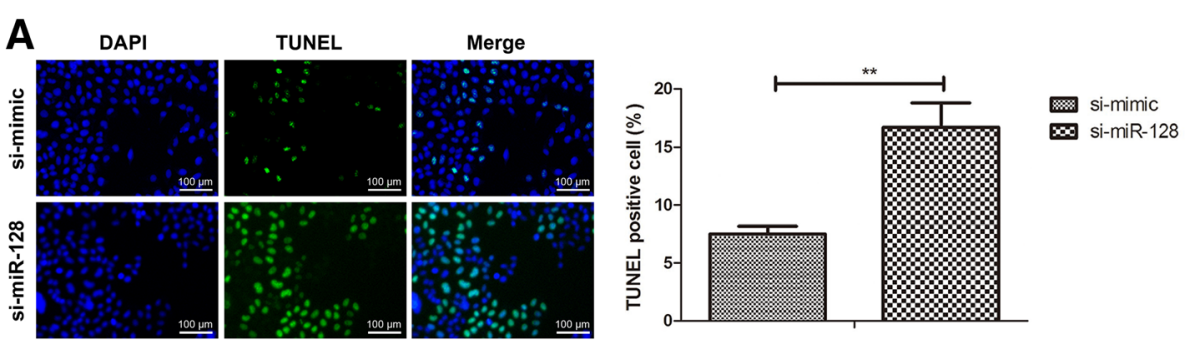

B
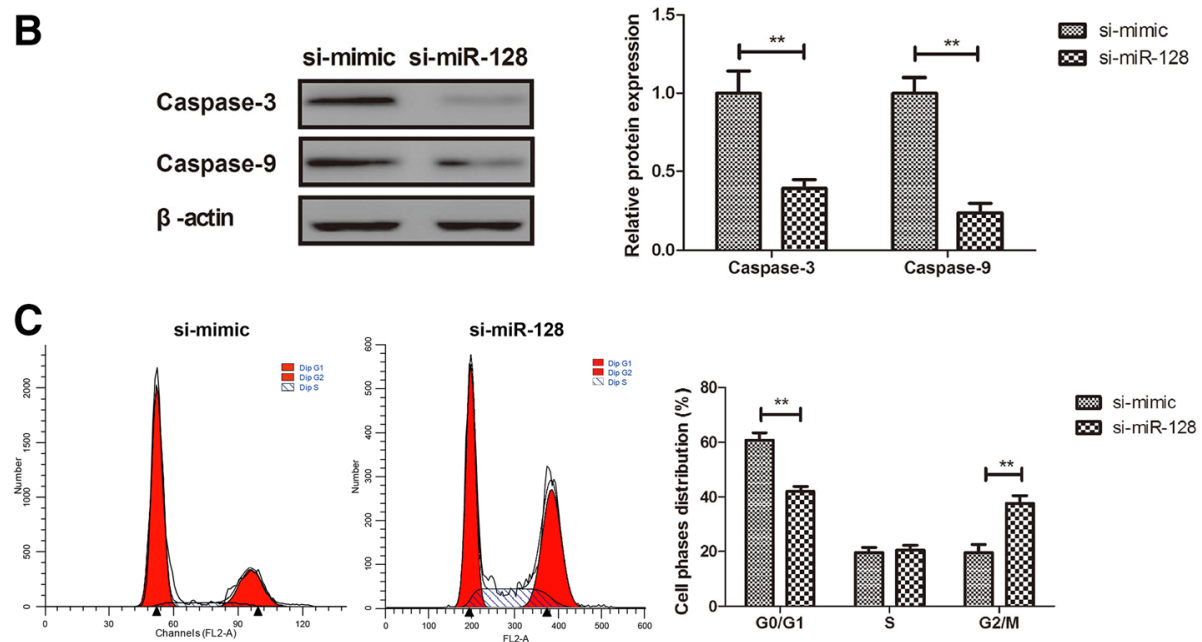

D

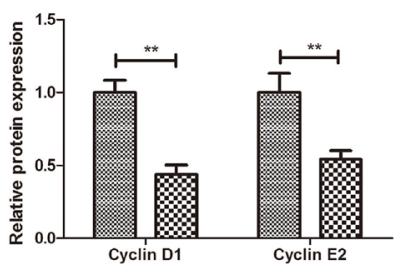

Fig. 3 Knockdown of miR-128 induced apoptosis and arrested cell cycle of Mg63 cells. a si-miR-128 induced apoptosis of Mg63 cells. b si-miR128 increased caspase-3 and caspase-9 expression in Mg63 cells. c si-miR-128 arrested G2/M phase in Mg63 cells determined by flow cytometry analysis. $\mathbf{d}$ Expression of cyclin D1 and cyclin E2 in si-miR-128-transfected Mg63 cells. ${ }^{* *} P<0.01$ vs. Si-NC 
compared to the control, knockdown of miR-128 inhibited Mg63 cells proliferation $(P<0.01$; Fig. 2a), migration $(P<0.01$; Fig. $2 \mathrm{~b})$, and invasion $(P<0.01$; Fig. 2c). Furthermore, knockdown of miR-128 decreased BMP-2 and VEGF protein expression in Mg63 cells $(P<0.01$; Fig. 2 d $)$.

\section{Knockdown of miR-128 induced apoptosis and arrested cell cycle of Mg63 cells}

In order to examine the inhibitory effects of miR-128, apoptosis and cell cycle were evaluated in miR-128 knockdown Mg63 cells. As shown in Fig. 3, compared to the control, knockdown of miR-128 markedly induced apoptosis of Mg63 cells $(P<0.01$; Fig. 3b) while it increased caspase- 3 and caspase- 9 protein expression in Mg63 cells $(P<0.01$; Fig. 3b). Flow cytometry analyses demonstrated that miR-128 knockdown arrested G2/M phase in Mg63 cells $(P<0.01$; Fig. 3c). Protein expression of Cyclin D1 and Cyclin E2 was downregulated in
miR-128 knockdown Mg63 cells compared to miR-128 mimic-transfected Mg63 cells $(P<0.01$; Fig. $3 \mathrm{~d})$.

\section{Knockdown of miR-128 suppressed the activation of the Wnt/ $\beta$-catenin and EMT signaling pathways in Mg63 cells} This study demonstrated whether knockdown of miR128 changed the Wnt/ $\beta$-catenin and EMT signaling pathways. Luciferase activity assay presented that relative luciferase activity was decreased in si-miR-128 Mg63 cells compared with si-NC Mg63 cells $(P<0.01)$, and miR-128 targeted to 3'UTR of Wnt (Fig. 4a). Immunoblotting analysis demonstrated that, compared to the control, knockdown of miR-128 downregulated Wnt and $\beta$-catenin protein expression $(P<0.01$; Fig. $4 \mathrm{~b})$. Results also showed that genetic knockdown of miR-128 dramatically decreased the protein expression of the epithelial markers E-cadherin, and the mesenchymal markers vimentin and fibronectin in Mg63 cells $(P<$ 0.01; Fig. 4c).

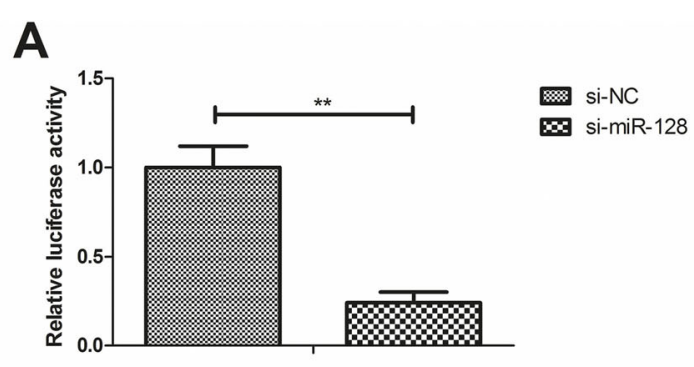

B
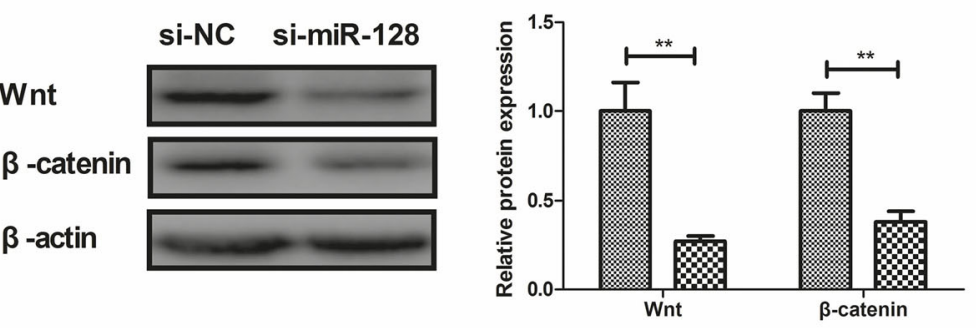

si-NC

si-miR-128

C

si-NC si-miR-128
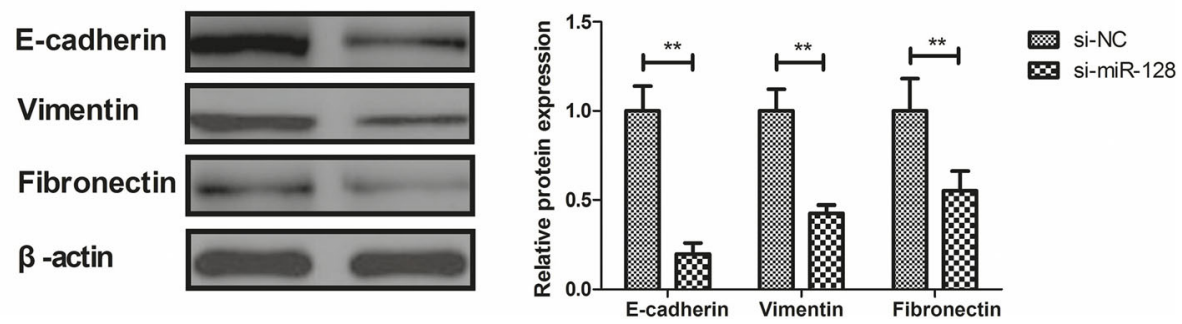

Fig. 4 Si-miR-128 suppressed protein expression of Wnt/ $\beta$-catenin and EMT in Mg63 cells. a Putative binding sites between Wnt 3'UTR and miR128. b si-miR-128 decreased Wnt and $\beta$-catenin expression in Mg63 cells. c si-miR-128 decreased the epithelial markers E-cadherin and the mesenchymal markers vimentin and fibronectin in Mg63 cells. ${ }^{*} P<0.01$ vs. si-NC 


\section{Activation of Wnt/EMT blocked miR-128-inhibited cells proliferation and migration of $\mathrm{Mg} 63$ cells}

We further analyzed the role Wnt/EMT activation in miR-128-inhibited cell proliferation and migration in Mg63 cells. As indicated in Fig. 5a, Wnt and $\beta$-catenin expression was obviously promoted in Wnt overexpressed Mg63 cells. However, knockdown of miR-128 inhibited Wnt and $\beta$-catenin protein expression in Wnt overexpressed (pWnt) Mg63 cells $(P<0.01)$. Overexpression of Wnt blocked miR-128-inhibited proliferation (Fig. 5b), migration (Fig. 5c), and invasion (Fig. 5d) in Mg63 cells (all $P<0.01$ ). Similarly, high expression of E-cadherin was found in E-cadherin overexpressed (pE-cad) Mg63 cells. si-miR-128 decreased protein expression of the epithelial markers Ecadherin and the mesenchymal markers vimentin and fibronectin in Mg63 cells $(P<0.01$; Fig. 5e). Moreover, EMT activation canceled miR-128-suppressed proliferation (Fig. 5f), migration (Fig. 5g), and invasion (Fig. 5h) in Mg63 cells (all $P<0.01$ ).

\section{Knockdown of miR-128 suppressed tumor growth in xenograft models}

To determine whether miR-128 knockdown suppressed bone tumor growth, si-miR-128- or si-miR-mimic knockdown Mg63 cells were subcutaneously injected into the flanks of experimental mice. As shown in Fig. 6a, exogenous knockdown of miR-128 markedly inhibited tumor regeneration in bone neoplasms xenograft models during 10 weeks observation compared to the control mice $(P<$ 0.01 ). Immunohistochemistry staining showed that miR128 knockdown decreased expression of Wnt, $\beta$-catenin,

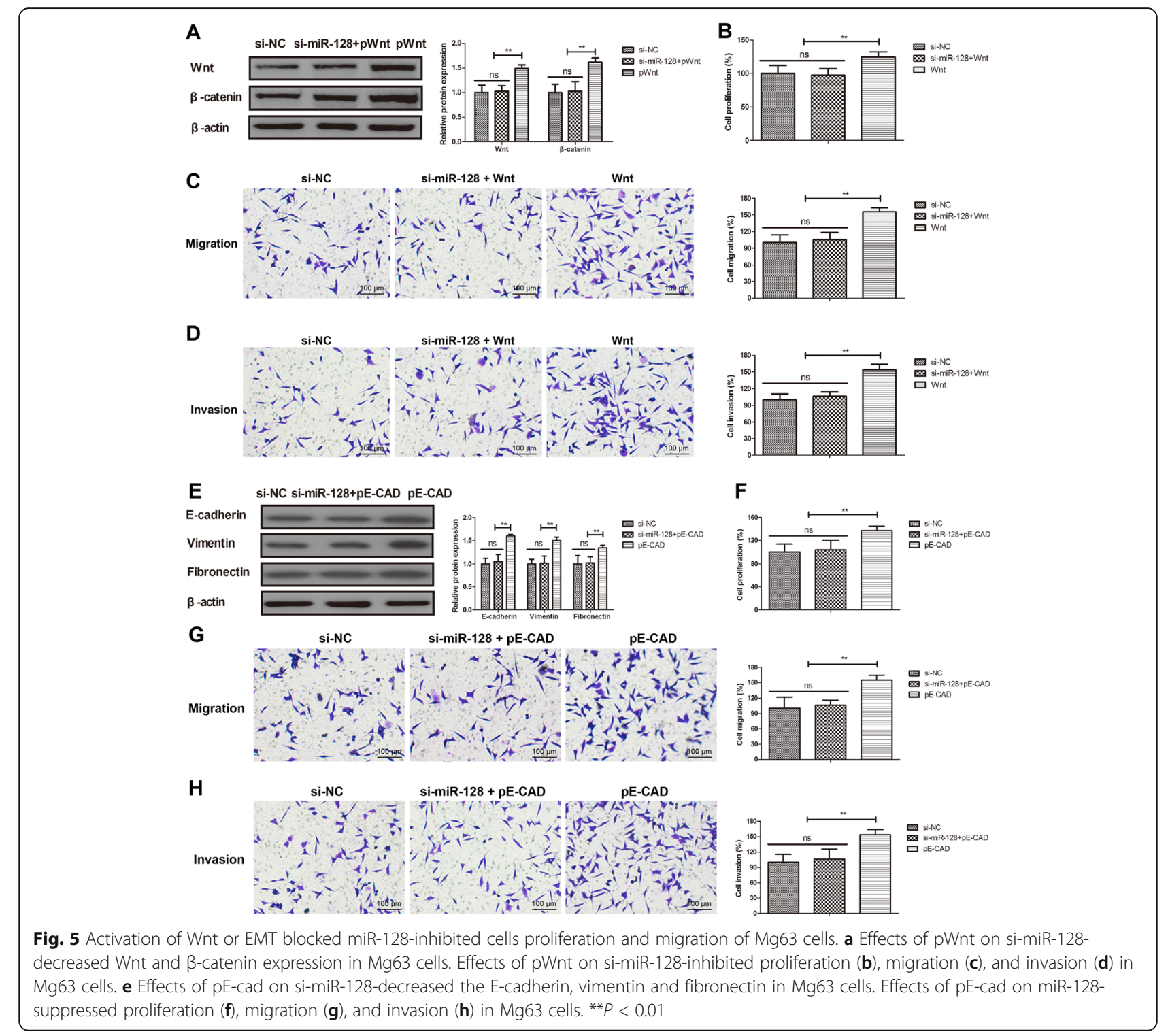



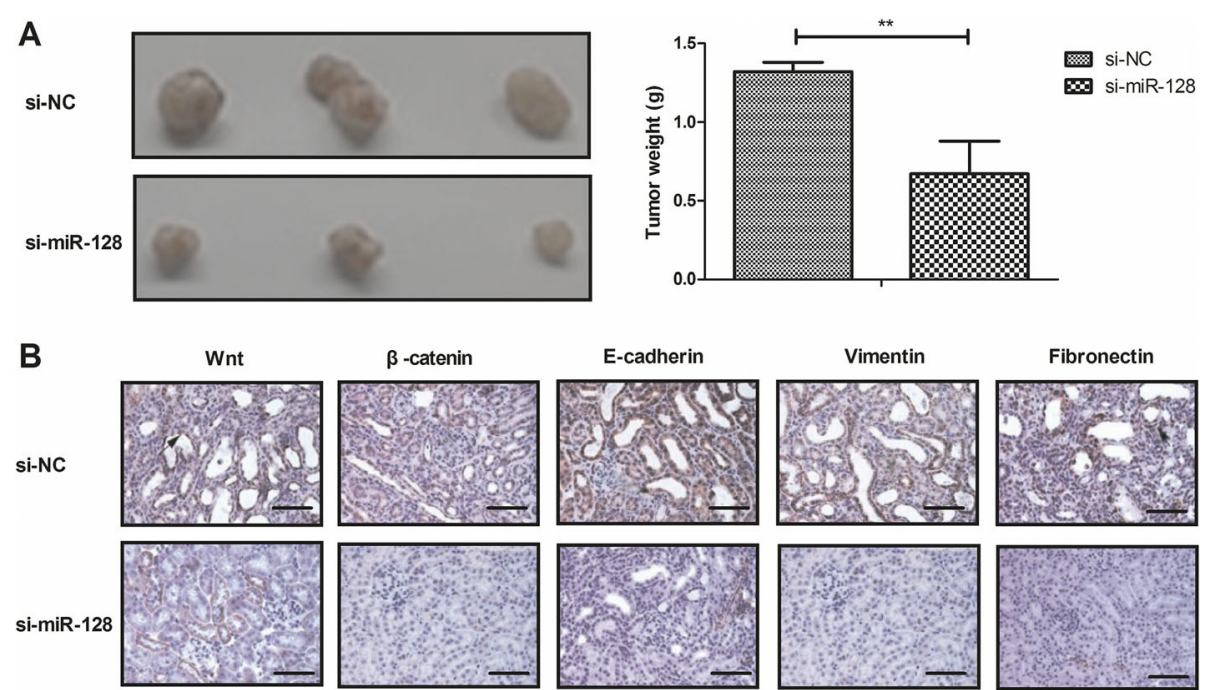

Fig. 6 Si-miR-128 suppressed tumor growth in xenograft models. a Knockdown of miR-128 inhibited tumor growth in xenograft models during 10 weeks observation. $\mathbf{b}$ Knockdown of miR-128 decreased the Wnt/ $\beta$-catenin and EMT signal pathways in tumor tissue. Magnification, $\times 40 .{ }^{* *} P$ $<0.01$ vs. Si-NC

E-cadherin, vimentin, and fibronectin, indicating that miR-128 knockdown inhibited the Wnt/B-catenin and EMT signaling pathways in tumor tissues of bone neoplasms (Fig. 6b).

\section{Discussion}

miRNAs are involved in the diagnosis of OA as well as in its treatment $[29,30]$. The data in a previous study indicated that the miR-128 downregulation inhibits osteosarcoma cell proliferation and migration phenotype [31]. Activation of $\mathrm{Wnt} / \beta$-catenin signaling pathways play essential roles and may rescue chemotherapy drug resistance by targeting Beclin 1 in osteosarcoma cells [32]. Blocking EMT can suppress osteosarcoma cell proliferation by inducing apoptosis [33]. In this study, in vitro and in vivo data demonstrate that miR-128 expression is upregulated in both bone cancer tissue and Mg63 cells. Further, miR-128 has a regulatory function in bone cancer cell proliferation, metastasis, apoptosis, and tumor regeneration. Mechanistically, findings in the current study indicate that knockdown of miR-128 in Mg63 cells interferes with the Wnt/ $\beta$-catenin and EMT signaling pathways. Of note, miR-128 knockdown inhibited cell growth, migration, and invasion partly through the suppression of the Wnt/ $\beta$-catenin and EMT signaling pathways in Mg63 cells.

Currently, knockdown of miR-128 in breast tumorinitiating cells was reported to induce chemotherapeutic resistance, which contributes to chemotherapeutic resistance in breast cancers by targeting of Bmi-1 and ATP binding cassette subfamily $\mathrm{C}$ member 5 (ABCC5) [34]. Previous findings provided the evidence that miR-128 may serve as a potential therapeutic target in glioma by inhibition of tumor angiogenesis via p70S6K1 [35]. In addition, miR-128 enhances dendritic cell-mediated antitumor immunity via targeting p38 mitogen activated protein kinase (MAPK) signaling pathway in C57BL/6 mice bearing B16 melanoma [36]. Data in this study found that miR-128 knockdown inhibits bone cancer cells proliferation, migration, invasion, and promotes apoptosis and cell cycle. Results demonstrated that miR128 knockdown effectively induced osteosarcoma cell apoptosis via decreasing caspase- 3 and caspase- 9 and arrested Mg63 cells at G2/M phase via inhibition of cyclin D1 and cyclin E2. The potential roles need to be further explored to clarify the regulatory function of miR-128 in bone tumor cells in future.

Studies have found that the Wnt/ $\beta$-catenin and EMT signaling pathways are associated with tumor cell proliferation, apoptosis, and cell cycle regulation [37-39]. Aberrant activation of Wnt signaling has been implicated in human osteosarcoma, and Wnt/ $\beta$-catenin signaling plays the critical role in human osteosarcoma pathogenesis and growth [37]. Inactivation of the Wnt/ beta-catenin signaling inhibits angiogenesis and induces cell apoptosis in osteosarcoma cells by inducing autophagy [38]. Inhibition of EMT serves as a tumor suppressor in osteosarcoma by suppressing the progression and metastasis [39]. Furthermore, EMT inactivation inhibited proliferation, migration, invasion, and in osteosarcoma by targeting zinc finger E-box-binding protein 1 (ZEB1) through inactivation of c-Jun $\mathrm{N}$-terminal kinase (JNK) and JAK1/signal transducer and activator of transcription 3 (STAT3) pathways [25]. Data in this study found that knockdown of miR-128 suppresses the activation of the $\mathrm{Wnt} / \beta$-catenin and EMT signal pathways in bone 
neoplasms tissues and cells. However, activation of Wnt/ EMT blocked miR-128-inhibited cells proliferation and migration of bone neoplasms cells. Notably, in vivo assay showed that disrupting miR-128 expression in Mg63 cells presents small tumor weight compared with miRmimic transfected cells. The reduced growth of miR-128 knockdown tumors show suppression of Wnt/beta-catenin and EMT signaling pathways, suggesting inhibition of Wnt/beta-catenin and EMT might contribute to tumor growth inhibition. Therefore, further analyses are needed to clearly elucidate miR-128 knockdown mechanisms in vitro and in vivo.

In summary, data in the current study demonstrates that the high miR-128 expression is found in bone neoplasms tissues and cells. miR-128 knockdown inhibits bone cancer cell proliferation and metastasis, and tumor growth through suppression of the $\mathrm{Wnt} / \beta$-catenin and EMT signaling pathways. It is indicated that targeting miR-128 may provide new avenues for the research of a potential therapeutic agent and clinical biomarker of bone cancer growth and metastasis.

\section{Abbreviations}

miR-218: miRNA-128; miRNAs: microRNAs; miR-128: miRNA-128; qRT-

PCR: Quantitative reverse transcription-polymerase chain reaction; pWnt: Wht overexpressing; $\mathrm{PE}$-cad: E-cadherin overexpression plasmid;

PVDF: Polyvinylidene fluoride; WT: Wild-type; MUT: Wnt reporter and mutant type; EMT: Epithelial-mesenchymal transition; TUNEL: Terminal

deoxynucleotidyl transferase-mediated dUTP nick end labeling; Bax: B cell lymphoma 2-associated X; BMI-1: B cell-specific Moloney murine leukemia virus insertion site 1; TGFBR1: transforming growth factor beta receptor 1; SD: Standard deviation; ANOVA: One-way analysis of variance; SPSS: Statistical Product and Service Solutions software; IHC: Immunohistochemistry; RIPA: Radioimmunoprecipitation assay; DAPI: 4',6'-diamidino-2-phenylindole; PBS: Phosphate buffer saline; SDS-PAGE: Sulfate-polyacrylamide gel electrophoresis; BSA: Bovine serum albumin; DMEM: Dulbecco's modified Eagle medium; FBS: Fetal bovine serum; MAPK: Mitogen-activated protein kinase; ZEB1: Zinc finger E-box-binding protein 1; JNK: c-Jun N-terminal kinase; STAT3: Signal transducer and activator of transcription 3

\section{Acknowledgements}

Not applicable.

\begin{abstract}
Authors' contributions
KS was the guarantor of integrity of the entire study. YL and KS undertook study concepts and design. YL, KS, and XL took definition of intellectual content. YL, JW, and JP took literature research and clinical studies. YL was responsible for experimental studies, manuscript preparation, and editing. JW and JP undertook data acquisition and analysis. KS and XLwere responsible for manuscript review. The author(s) read and approved the final manuscript.
\end{abstract}

\section{Funding}

This study was supported by Science and Technology Foundation of Yuzhong District in Chongqing (20160131).

\section{Availability of data and materials}

The analyzed data sets generated during the study are available from the corresponding author on reasonable request.

\section{Ethics approval and consent to participate}

The clinical protocol was approved by the Ethical Committee of University of the Chinese Academy of Sciences. The written informed consent was obtained from all individuals.

\section{Consent for publication}

Informed consent was obtained from all individual participants included in the study.

\section{Competing interests}

The authors declare that they have no competing interests.

Received: 21 August 2020 Accepted: 17 December 2020

Published online: 20 January 2021

\section{References}

1. Bandyopadhyay O, Biswas A, Bhattacharya BB. Bone-cancer assessment and destruction pattern analysis in long-bone X-ray image. J Digital Imaging. 2019;32(2):300-13.

2. Li W, Luo X, Liu Z, Chen Y, Li Z. Prognostic value of C-reactive protein levels in patients with bone neoplasms: A meta-analysis. PloS one. 2018;13: e0195769.

3. Syrovatkina $V$, Huang $X Y$. Signaling mechanisms and physiological functions of g-protein Galpha13 in blood vessel formation, bone homeostasis, and cancer. Protein Science. 2019:28(2):305-12.

4. Chen G, Gong H, Wang T, Wang J, Han Z, Bai G, Han S, Yang X, Zhou W, Liu T, Xiao J. SOSTDC1 inhibits bone metastasis in non-small cell lung cancer and may serve as a clinical therapeutic target. Int J Molecular Med. 2018;42: 3424-36.

5. Loriot Y, Massard C, Fizazi K. Recent developments in treatments targeting castration-resistant prostate cancer bone metastases. Ann Oncol. 2012;23: 1085-94.

6. Vassiliou V, Kardamakis D, Quattrocchi CC, Dell'aia P, Beomonte ZB. Types of bone metastases in women with breast cancer undergoing systemic treatments. La Radiologia Medica. 2008;113:771-2 author reply 772-773.

7. Saad F. Bone-directed treatments for prostate cancer. Hematol Oncol Clinics North America. 2006;20:947-63

8. Leger AF, Pellan M, Dagousset F, Chevalier A, Keller I, Clerc J. A case of stunning of lung and bone metastases of papillary thyroid cancer after a therapeutic dose $(3.7 \mathrm{GBq})$ of 1311 and review of the literature: implications for sequential treatments. Brit J Radiol. 2005;78:428-32.

9. Higano CS. Understanding treatments for bone loss and bone metastases in patients with prostate cancer: a practical review and guide for the clinician. Urologic Clin North America. 2004;31:331-52.

10. Zhou K, Yue P, Ma F, Yan H, Zhang Y, Wang C, Qiu D, Hua Y, Li Y. Interpreting the various associations of MiRNA polymorphisms with susceptibilities of cardiovascular diseases: current evidence based on a systematic review and meta-analysis. Medicine. 2018;97:e10712.

11. Wen J, Lv Z, Ding H, Fang X, Sun M. Association of miRNA biosynthesis genes DROSHA and DGCR8 polymorphisms with cancer susceptibility: a systematic review and meta-analysis. Bioscience Reports. 2018;38(3): BSR20180072.

12. Katoh $\mathrm{Y}$, Katoh M. Hedgehog signaling, epithelial-to-mesenchymal transition and miRNA (review). Int J Mole Med. 2008;22:271-5.

13. Huang J, Liang $Y, X u M$, Xiong J, Wang D, Ding Q. MicroRNA-124 acts as a tumor-suppressive miRNA by inhibiting the expression of Snail2 in osteosarcoma. Oncol Letters. 2018:15:4979-87.

14. Leao R, van Agthoven T, Figueiredo A, Jewett MAS, Fadaak K, Sweet J, Ahmad AE, Anson-Cartwright L, Chung P, Hansen A, Warde P, CasteloBranco P, O'Malley M, Bedard PL, Looijenga LHJ, Hamilton RJ. Serum miRNA predicts viable disease after chemotherapy in patients with testicular nonseminoma germ cell tumor. J Urol. 2018;200:126-35.

15. Baltruskeviciene E, Schveigert D, Stankevicius V, Mickys U, Zvirblis T, Bublevic J, Suziedelis K, Aleknavicius E. Down-regulation of miRNA-148a and miRNA$625-3 p$ in colorectal cancer is associated with tumor budding. BMC Cancer. 2017;17:607.

16. M'Boutchou MN, van Kempen LC. Analysis of the tumor microenvironment transcriptome via nanostring mRNA and miRNA expression profiling. Methods Mole Biol. 2016;1458:291-310.

17. Guo L, Yuan J, Xie N, Wu H, Chen W, Song S, Wang X. miRNA-411 acts as a potential tumor suppressor miRNA via the downregulation of specificity protein 1 in breast cancer. Mole Med Reports. 2016;14: 2975-82.

18. Slattery ML, Herrick JS, Mullany LE, Wolff E, Hoffman MD, Pellatt DF, Stevens JR, Wolff RK. Colorectal tumor molecular phenotype and miRNA: expression profiles and prognosis. Modern Pathol. 2016;29:915-27. 
19. Gambari R, Brognara E, Spandidos DA, Fabbri E. Targeting oncomiRNAs and mimicking tumor suppressor miRNAs: Nuew trends in the development of miRNA therapeutic strategies in oncology (Review). Int J Oncol. 2016:49:5-32

20. Ell B, Mercatali L, Ibrahim T, Campbell N, Schwarzenbach H, Pantel K, Amadori D, Kang Y. Tumor-induced osteoclast miRNA changes as regulators and biomarkers of osteolytic bone metastasis. Cancer Cell. 2013:24:542-56.

21. Ji S, Shao G, Lv X, Liu Y, Fan Y, Wu A, Hu H. Downregulation of miRNA-128 sensitises breast cancer cell to chemodrugs by targeting Bax. Cell Biol Int. 2013:37:653-8.

22. Jin M, Zhang T, Liu C, Badeaux MA, Liu B, Liu R, Jeter C, Chen X, Vlassov AV, Tang DG. miRNA-128 suppresses prostate cancer by inhibiting BMl-1 to inhibit tumor-initiating cells. Cancer Research. 2014; 74:4183-95

23. Chang J, Li Y, Wang X, Hu S, Wang H, Shi Q, Wang Y, Yang Y. Polyphyllin I suppresses human osteosarcoma growth by inactivation of Wnt/beta-catenin pathway in vitro and in vivo. Scientific Reports. 2017; 7:7605.

24. Wang X, Liang X, Liang H, Wang B. SENP1/HIF-1alpha feedback loop modulates hypoxia-induced cell proliferation, invasion, and EMT in human osteosarcoma cells. J Cell Biochem. 2018;119:1819-26.

25. Jiang R, Zhang C, Liu G, Gu R, Wu H. MicroRNA-126 inhibits proliferation, migration, invasion, and EMT in osteosarcoma by targeting ZEB1. J Cell Biochem. 2017;118:3765-74.

26. Zhang M, Wang D, Zhu T, Yin R. RASSF4 Overexpression inhibits the proliferation, invasion, EMT, and Wnt signaling pathway in osteosarcoma cells. Oncology Research. 2017;25:83-91.

27. Livak KJ, Schmittgen TD. Analysis of relative gene expression data using real-time quantitative PCR and the 2(-Delta Delta C(T)) Method. Methods. 2001;25:402-8.

28. Fernandez-Pol S, Ma L, Ohgami RS, Arber DA. Immunohistochemistry for p53 is a useful tool to identify cases of acute myeloid leukemia with myelodysplasia-related changes that are TP53 mutated, have complex karyotype, and have poor prognosis. Modern Pathol. 2017;30: 382-92.

29. Giordano L, Porta GD, Peretti GM, Maffulli N. Therapeutic potential of microRNA in tendon injuries. Brit Med Bull. 2020;133(1):79-94.

30. Oliviero A, Della Porta G, Peretti GM, Maffulli N. MicroRNA in osteoarthritis: physiopathology, diagnosis and therapeutic challenge. Brit Med Bull. 2019; 130(1):137-47.

31. Kong D, Zhang Z. NAIF1 suppresses osteosarcoma progression and is regulated by miR-128. Cell Biochem Function. 2018;36(8):443-9.

32. Tao H, Chen F, Liu H, Hu Y, Wang Y, Li H. Wnt/beta-catenin signaling pathway activation reverses gemcitabine resistance by attenuating Beclin1mediated autophagy in the MG63 human osteosarcoma cell line. Mole Med Reports. 2017;16:1701-6.

33. Wang L, Xue GB. Catalpol suppresses osteosarcoma cell proliferation through blocking epithelial-mesenchymal transition (EMT) and inducing apoptosis. Biochem Biophysical Res Communications. 2018; 495:27-34.

34. Zhu Y, Yu F, Jiao Y, Feng J, Tang W, Yao H, Gong C, Chen J, Su F, Zhang Y, Song E. Reduced miR-128 in breast tumor-initiating cells induces chemotherapeutic resistance via Bmi-1 and ABCC5. Clin Cancer Res. 2011;17: 7105-15.

35. Shi ZM, Wang J, Yan Z, You YP, Li CY, Qian X, Yin Y, Zhao P, Wang YY, Wang $X F$, Li MN, Liu LZ, Liu N, Jiang BH. MiR-128 inhibits tumor growth and angiogenesis by targeting p70S6K1. PloS one. 2012;7:e32709.

36. Liang X, Shangguan W, Zhang M, Mei S, Wang L, Yang R. miR-128 enhances dendritic cell-mediated anti-tumor immunity via targeting of p38. Mole Med Reports. 2017;16:1307-13.

37. Fang F, VanCleave A, Helmuth $R$, Torres $H$, Rickel $K$, Wollenzien $H$, Sun $H$, Zeng E, Zhao J, Tao J. Targeting the Wnt/ $\beta$-catenin pathway in human osteosarcoma cells. Oncotarget. 2018;9(95):36780-92.

38. Li X, Lu Q, Xie W, Wang Y, Wang G. Anti-tumor effects of triptolide on angiogenesis and cell apoptosis in osteosarcoma cells by inducing autophagy via repressing Wnt/beta-Catenin signaling. Biochem Biophysical Res Communications. 2018;496:443-9.

39. Ma L, Xue W, Ma X. GATA3 is downregulated in osteosarcoma and facilitates EMT as well as migration through regulation of slug. Onco Targets Therapy. 2018;11:7579-89.

\section{Publisher's Note}

Springer Nature remains neutral with regard to jurisdictional claims in published maps and institutional affiliations.

\section{Ready to submit your research? Choose BMC and benefit from:}

- fast, convenient online submission

- thorough peer review by experienced researchers in your field

- rapid publication on acceptance

- support for research data, including large and complex data types

- gold Open Access which fosters wider collaboration and increased citations

- maximum visibility for your research: over $100 \mathrm{M}$ website views per year

At $\mathrm{BMC}$, research is always in progress.

Learn more biomedcentral.com/submissions 